\title{
Rapid Prototyping High-Performance MR Safe Pneumatic Stepper Motors
}

\author{
Vincent Groenhuis and Stefano Stramigioli
}

\begin{abstract}
In this paper we show that MR safe pneumatic stepper motors can be constructed using rapid prototyping techniques such as 3-D printing and laser-cutting. The designs are lightweight, metal-free and fully customizable. Besides MR safe robotic systems, other potential applications include high-voltage switchgear and nuclear power plant systems which also restrict electric actuation. In addition, it can be applied to other actuation systems where pressurized air is available and lightweight, rapid prototypeable actuators are needed.

Five pneumatically-driven linear and rotational stepper motors have been developed with forces up to $330 \mathrm{~N}$, torques up to $3.7 \mathrm{Nm}$, stepping frequency up to $320 \mathrm{~Hz}$, dimensions ranging from $25 \mathrm{~mm}$ to $80 \mathrm{~mm}$, free of backlash and power up to $26 \mathrm{~W}$. All five motors are constructed from six 3-D printed parts and four seals, held together by nylon screws or clips. The described stepper motors outperform state-of-the-art plastic pneumatic stepper motor designs, both in specifications and in manufacturability.
\end{abstract}

\section{INTRODUCTION}

Rotational stepper motors are widely used in actuation of mechanical devices. Off-the-shelf stepper motors are generally driven by electromagnetic forces, constructed from an electromagnetic stator and a permanent magnet rotor. The stator has two or more phases, each consisting of an electromagnetic coil which can generate a magnetic field to apply a torque on the rotor. By driving the coils with appropiate waveforms, step-wise rotational motion is achieved. A rack-and-pinion or leadscrew mechanism can convert rotational to translational movements, but pure electromagnetic linear stepper motors also exist in which the stator is a track of magnets on which a moving platform with electromagnetic coils can slide back and forth.

One application for stepper motors is in medical robotics. In breast cancer screening and diagnosis, an MRI-guided breast biopsy may be required to acquire tissue samples for pathology assessment to determine if a lesion is malignant. The current manual MRI-guided breast biopsy procedure is inaccurate and would benefit from a robotically-driven needle positioning and insertion system that can operate inside the bore. Such a robot needs to be driven by MR safe/conditional actuators. Electromagnetic motors are not an option due to interference with the strong magnetic field, which would pose safety hazards and distort MRI scans. Taking the available space and the range of forces into account, we can specify the requirements for a linear actuator as follows: free of conductive materials, size under $50 \mathrm{~mm}$, positional accuracy

V. Groenhuis and S. Stramigioli are with Robotics and Mechatronics, University of Twente, Enschede, The Netherlands. S. Stramigioli is also with ITMO, Russia. E-mail: v.groenhuis@utwente.nl

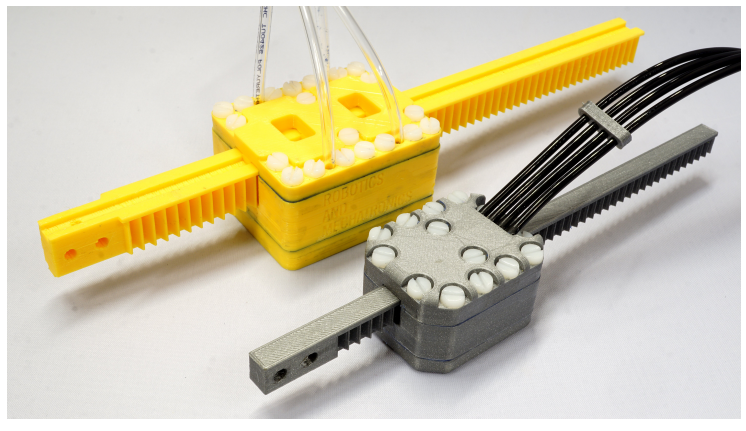

(a) Linear motors: T-63 (top) and T-49 (bottom).

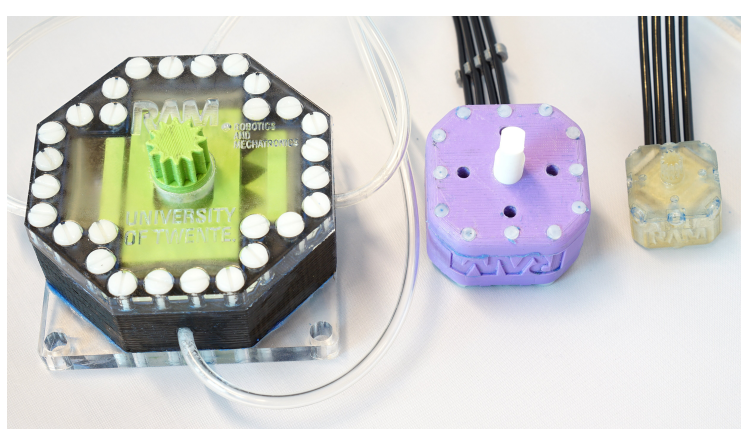

(b) Rotational motors: R-80 (left), R-44 (middle) and R-25 (right).

Fig. 1: Pneumatic stepper motors.

$1 \mathrm{~mm}$ or better, force at least $50 \mathrm{~N}$ and velocity up to $5 \mathrm{~mm} / \mathrm{s}$. The motor must be controllable from outside the Faraday cage of the MRI scanner, i.e. over a distance of at least $5.0 \mathrm{~m}$, and the motor should be scalable and rapid prototypeable so that motors can be easily replicated and adapted for specific joints within particular kinematic configurations.

\section{A. State of the art}

Since electromagnetic motors are not MR safe or conditional, various alternative actuation methods have been investigated. While hydraulic [4], [5], piezo [6], [7], cable transmission [8], MRI-driven [9], air turbine [10], flexible fluidic actuators [11], direct-acting pneumatic actuators [12] and unidirectional pneumatic stepper motors [13] have been demonstrated, actuation by metal-free bidirectional pneumatic stepper motors has several important advantages. They are inherently MR safe, tolerant for small air leakages, can be controlled with a standard pneumatic valve manifold and allow for step-wise position control without need for a position feedback system. 

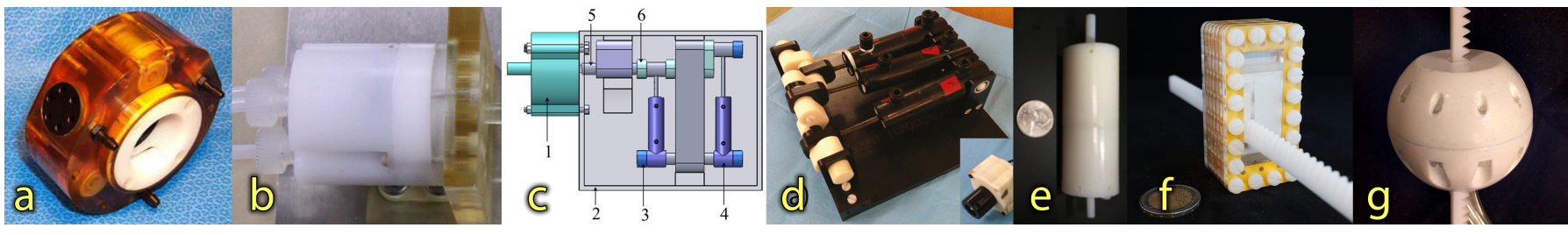

Fig. 2: State-of-the-art pneumatic stepper motors: a. Stoianovici et al. (2007), b. Sajima et al. (2012), c. Chen et al. (2014), d. Secoli et al. (2015), e. Guo et al. (2016), f. Groenhuis and Stramigioli (2014), g. Groenhuis et al. (2015).

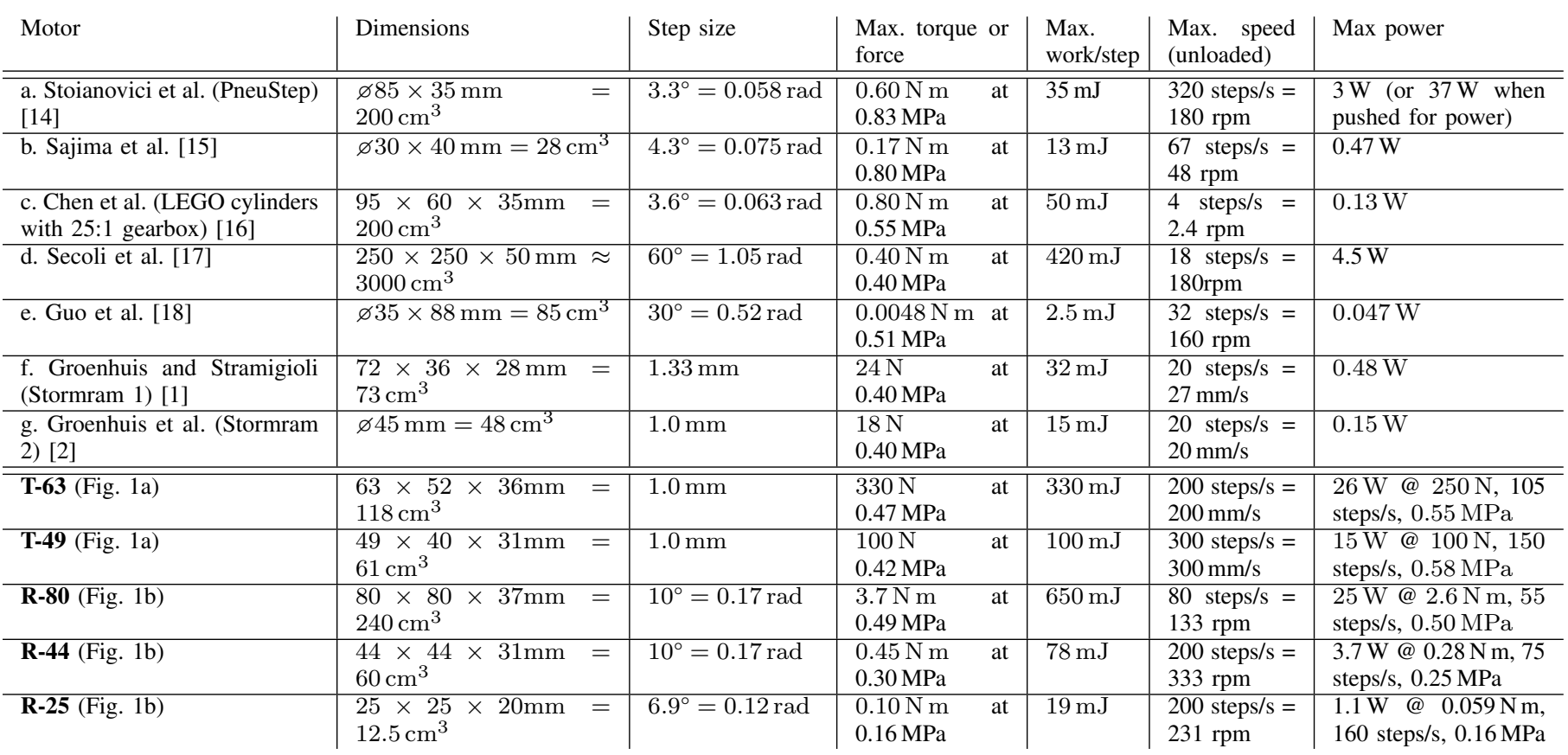

TABLE I: Specifications of state-of-the-art pneumatic stepper motors (a-g), and the five motors presented in this paper.

Figure 2 shows, and Table I (a-g) lists a number of MR safe/conditional pneumatic stepper motors found in literature. They are compared by specifications such as motor dimensions, step size, force, stepping frequency and power. Because there is no uniform test protocol, not all figures are directly comparable. This especially applies to the maximum power, for which certain authors push the motor outside the normal operation range using short tubes, high pressure and fast valves, while other authors only perform measurements using a practical setup with longer tubes and/or slower valves. It might therefore also be useful to compare the maximum work (force times displacement) performed in one single step, hereby ignoring the stepping frequency.

Stoianovici et al. developed the PneuStep (Figure 2a) [14]. This design avoids sliding parts as much as possible by using diaphragm sealing and ball bearings. It provides $3 \mathrm{~W}$ output power in normal operation range, and up to $37 \mathrm{~W}$ when pushed for power. However, the PneuStep design is relatively large and also very complex to manufacture due to the 26 different components made out of 11 materials. The design of Sajima et al. (Figure 2b) is much more compact and easy to manufacture, and still offers good properties considering its size [15]. The Lego-powered motor by Chen et al. (Figure 2c) performs much work per step and uses a gearbox to obtain high output torque, but it was only tested at low speeds (4 steps/sec) resulting in a rated power of $0.13 \mathrm{~W}$ which is relatively weak for its size $^{1}$ [16]. Also, it makes use of commercial Lego cylinders, limiting the rapid prototypeability. Secoli et al. developed a powerful three-piston motor (Figure 2d), but with a volume of $3000 \mathrm{~cm}^{3}$ it is relatively large [17]. The design of Guo et al. (Figure 2e) is innovative and easy to manufacture, but the current prototype has the smallest torque and power of all discussed designs [18].

Besides rotational stepper motors which could drive a spindle or rack-and-pinion mechanism to actuate linear motion, true linear stepper motors also have been developed. The authors of this paper, Groenhuis et al. developed two designs of different sizes (Figure 2f-g) produced by laser-cutting combined with 3-D printing, delivering up to $24 \mathrm{~N}$ of force. Due to the choice of valves, these have only been tested at speeds up to $20 \mathrm{steps} / \mathrm{s}$, delivering $0.48 \mathrm{~W}$ for the design used in the Stormram 1 robot [1], and $0.15 \mathrm{~W}$ for the more compact design in the Stormram 2 robot [2]. The Stormram 1 and 2 are robotic systems for breast biopsy. Excluding the needle, both of them are MR safe. To our knowledge, no other linear pneumatic stepper motors have been developed, but the generic mechanism has been described in a patent application [19].

\footnotetext{
${ }^{1}$ After communicating with the author, it was found out that the originally claimed $25 \mathrm{~W}$ of power was a miscalculation.
} 

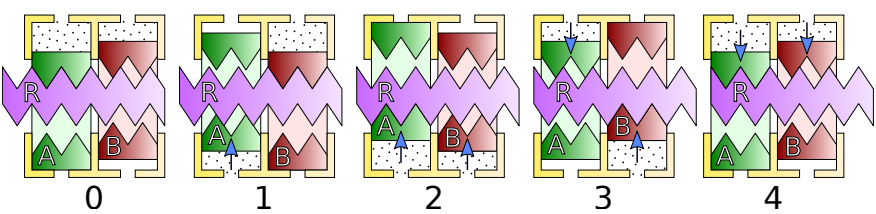

(a) Five consecutive motor states in a linear stepper motor. The pistons (A and $\mathrm{B}$ ) alternatingly move up and down, pushing the rack $(\mathrm{R})$ four steps to the right.

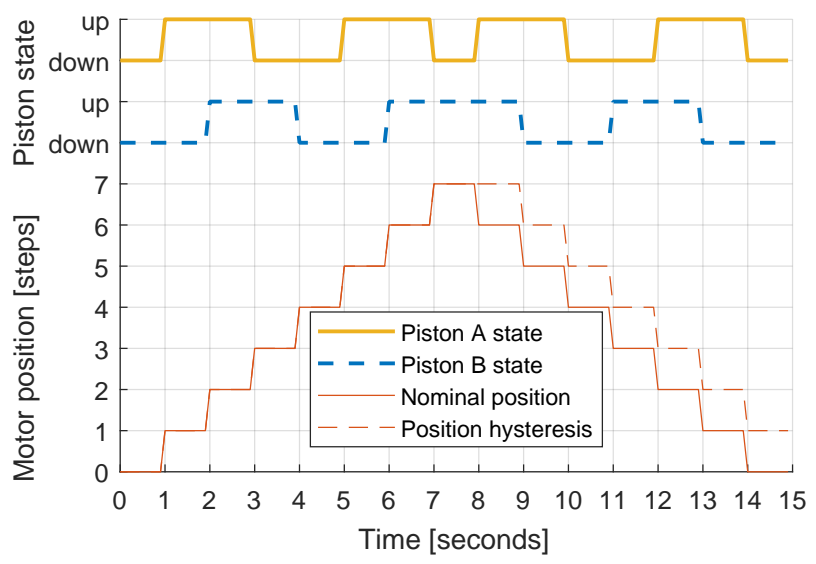

(b) Piston waveforms and corresponding motor position graph, without and with taking hysteresis into account.

Fig. 3: Operating principle of a linear stepper motor running at $1 \mathrm{~Hz}$, relating piston waveforms to the rack position.

None of these motors meet all requirements stated in Section I for our MR safe robot application. Certain motors have too large dimensions, while others do not meet the force and velocity requirements in an MRI environment. Furthermore, many motors are hard to replicate and therefore a new design is required.

Besides the motors presented in this paper, two other novel motors that meet the stated requirements are published by the same authors [20]. The T-26 is a further miniaturized version of the T-63 presented in this paper, while the C-30 is a curved stepper motor similar to the T-26 but in which the rack is curved to make a rotational motion.

\section{DESIGN AND PRODUCTION}

A systematic method for constructing novel linear and rotational stepper motors has been developed. Each motor consists of two pistons, which push against a rack (in linear motors) or geared axle (in rotational motors) by a wedge mechanism inside the pistons. Each piston moves back and forth in a double-acting cylinder, therefore a single motor is driven by four pneumatic tubes in total. This section describes the principle of operation, a study on teeth geometry, calculations on valve airflow, and two concrete stepper motor designs.

\section{A. Principle of operation}

Figure 3a shows five consecutive states of a linear stepper motor (labeled 0 to 4 ), and Figure $3 \mathrm{~b}$ the corresponding piston waveforms and position of the rack. The position of a motor is controlled by driving quadrature-encoded waveforms to the two cylinders.

Only one piston can be fully engaged to the rack (or gear). This is always the piston which was pressurized formerly. The reason is that the piston which was pressurized most recently, temporarily released its grip during its move, allowing the other piston to fully engage to the rack. This is also the reason why the actual position lags by one step from time $t=8$ when piston A switches state. The actual motor position not only depends on the current valve states, but also on the direction of the previous step. This phenomenon is called hysteresis and results in an offset between nominal and actual position, depending on the movement direction. However, this is by design since a consequence is that the motor has zero backlash, even under the presence of finite clearances in the cylinders. Furthermore, it is not envisaged to obtain a smooth motion, or enable any form of microstepping in the operation of the motors.

\section{B. Teeth geometry}

The geometry of the teeth determines important properties such as step size, wedge ratio, cylinder length and maximum load. Sharp teeth have a higher wedge ratio resulting higher force output, and allows for smaller step sizes for a given teeth depth, but 3-D printability and mechanical stresses put constraints on this and other design parameters.

For teeth printed with the Ultimaker 2, the step size cannot be smaller than $0.6 \mathrm{~mm}$ due to the $0.4 \mathrm{~mm}$ nozzle of the printer which causes rounding of the teeth.

Additional manufacturing effects such as seams, clearances in mechanical parts and bending under loads up to $0.1 \mathrm{~mm}$, cause additional deviations in the order of $0.2 \mathrm{~mm}$. To obtain a safe margin for such errors, a step size of $1.0 \mathrm{~mm}$ is chosen. As the step size is one quarter of the pitch size, the pitch size is then equal to $4.0 \mathrm{~mm}$.

The teeth depth now determines the tip angle and the wedge ratio. To avoid bending or cracking under high cyclic load, a stress analysis (by simulation and/or measurement) needs to be conducted to determine the maximum load. For a step size of $1.0 \mathrm{~mm}$, the maximal tip deflection under specified loads must not exceed $0.1 \mathrm{~mm}$ and the material stress must not exceed the maximum working stress, taking a sufficient margin of safety into account.

\section{Valve airflow}

Pressurized air is required to bring a piston into motion. The pressure in each chamber is controlled by a system of remote electromagnetic valves, supplied with system (gauge) pressure $P$. As the motor is placed inside the MRI scanner and electromagnetic valves (which are not MR safe) must be placed outside the Faraday cage of the MRI scanner, tubes of certain length are needed to connect the motor to the valves. With tube length $L_{t}$, inner diameter $d_{t}$ and cylinder bore volume $V_{c}$, the total air volume $V_{a}$ associated with pressurizing one cylinder bore is:

$$
V_{a}=\frac{\pi}{4} L_{t} d_{t}^{2}+V_{c}
$$




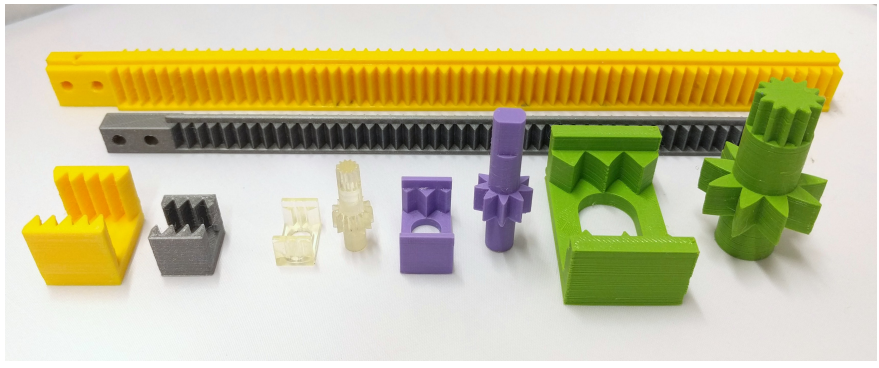

Fig. 4: Racks, toothed pistons and geared axles for the T-63 (yellow), T-49 (gray), R-80 (green), R-44 (purple) and R-25 (semi-transparent).

With $L_{t}=5.0 \mathrm{~m}, d_{t}=2.5 \mathrm{~mm}, V_{c}=1.0 \mathrm{~mL}$, we obtain $V_{a}=25.5 \mathrm{~mL}$. With a step size of $1 \mathrm{~mm}$ and a required velocity of $5 \mathrm{~mm} / \mathrm{s}$, a stepping frequency of $5 \mathrm{~Hz}$ is required. The average actual airflow through the valve is then $5 \cdot 25.5=128 \mathrm{~mL} / \mathrm{s}$, or $7.65 \mathrm{~L} / \mathrm{min}$. At a (gauge) pressure of $0.4 \mathrm{MPa}$, the standard airflow is $\frac{0.4}{0.1013} \cdot 7.65=30.2 \mathrm{~L} / \mathrm{min}$. This figure is a lower bound on the nominal valve airflow requirement. As the instantaneous airflow through a valve depends on the pressure drop, and there are also delay and friction effects in the tube, the actual airflow requirement is higher than $30.2 \mathrm{~L} / \mathrm{min}$. Due to the limitation of the complexity of pressurization wave propagation dynamics, measurements were performed instead to assess the pressurization time of a selected valve.

Valves of type Festo MHP2-MS1H-5/2-M5 were selected, which have a specified nominal standard airflow of $90 \mathrm{~L} / \mathrm{min}$ or $1.5 \mathrm{~L} / \mathrm{s}$. The theoretical minimum time required to fill a $25.5 \mathrm{~mL}$ volume to a pressure of $0.4 \mathrm{MPa}$ is then $\frac{0.4}{0.1013} \cdot \frac{25.5}{1500}=$ $67 \mathrm{~ms}$.

\section{Motor designs}

Five motors have been developed: two linear and three rotational ones. All five motors consist of six different custom components: the housing with top and bottom cover, two identical toothed pistons, four identical silicone seals and one rack or geared axle.

The main design challenges are in designing space-efficient cylinders that have relatively large bores (to provide high forces) and are well sealed (to minimize leakages), and in transferring the piston force efficiently to the rack or gear. Classic cylindrical-shaped pneumatic cylinders with protruding rods are difficult to rapid prototype, so a different method is used that essentially involves placing the rack or gear right through the pistons themselves, as employed earlier in lasercut pneumatics [1]. This eliminates the need of a protruding rod, simplifying and compacting the design. Another design choice is the use of rectangular-shaped cylinders, to maximize the force transferred to the rack for the same total motor volume and also for rapid prototypeability.

Figure 4 shows racks, gears and pistons of the different motors; it can be observed that the pistons are box-shaped with a cut-out space in its center, and series of teeth facing this cut-out space. Except for the R-25, the housing and covers are held together with M4 nylon screws into the tapped bottom cover, and sealed by blue silicone (Loctite 5926).

The box-shaped pistons are sealed by rectangular silicone rubber seals with slanted edges that are hand-cut from $2 \mathrm{~mm}$ silicone rubber using a 3-D printed cutting guide. For the R-25 motor, seals were laser-cut from $1 \mathrm{~mm}$ silicone rubber for more precise manufacturing due to the smaller size. The seals are preloaded in length and height by approximately $2 \%$. From experimentations, this factor was found to be the optimal tradeoff between minimizing sliding friction and air leakage.

Walls surrounding the rectangular cylinder bores must be thick enough to resist deformation under pressure. The reason is that the bore's cross-sectional shape is rectangular, while only circular cylinders have an optimal cross-sectional area to perimeter ratio. For $20 \mathrm{~mm}$ high cylinders, a wall thickness of $8 \mathrm{~mm}$ was chosen. FEM simulations have shown that deformation under pressure of $0.4 \mathrm{MPa}$ stays below $0.1 \mathrm{~mm}$, to keep air leakage to a minimum. Airflow measurements are performed to quantify this amount.

All rigid parts of the T-63 motor were produced using the Ultimaker 2. This 3-D printer produces parts using fused filament fabrication. The material used is Makerpoint PLA (Makerpoint Holding, Wageningen, The Netherlands). From its specifications, the Young's modulus $3.3 \mathrm{GPa}$ and ultimate tensile strength is $110 \mathrm{MPa}$. Using a safety factor of 4 , the design stress is $26 \mathrm{MPa}$.

Parts printed by fused filament fabrication method are not isotropic, which implies that actual tensile strength depends on the orientation of the load. Also, surface roughness varies significantly: of the bottom-facing faces, the lowermost one is smooth because it is printed directly on the glass print bed, while all other bottom-facing faces are rough. The topfacing faces are moderately rough, but the topmost one can be polished smooth by grinding. The side faces are all grooved due to the layered printing technique. For moving parts to slide with relatively low friction, surfaces have to match in smoothness: moderately rough surfaces must be coupled with smooth ones, and grooved surfaces must slide in the direction of the grooves. Vaseline (petroleum jelly) is used to lubricate the parts, minimizing friction and wear.

Because solid 3-D printed parts are generally not fully airtight due to the presence of small pores, a dilute solution of transparent ABS in acetone is applied to its walls after which these pores are sealed.

\section{E. T-63 linear motor}

The T-63 motor (Figure 1a, top) is a linear motor with dimensions $63 \times 52 \times 36 \mathrm{~mm}$. Figure 5 shows a CAD drawing of the motor.

The rack is constrained by linear guide rails. $4 \mathrm{~mm}$ tubes are mechanically clamped by purposely misaligning the pneumatic tube socket holes in the top cover and housing. For reasons described in Section II-B, a teeth pitch of $4 \mathrm{~mm}$ was chosen. The teeth depth, which is a tradeoff between high wedge ratio and short cylinder stroke, was chosen to be $5 \mathrm{~mm}$, resulting in a teeth tip angle of $43.6^{\circ}$.

The bore's cross-sectional area is $20 \mathrm{~mm} \times 20 \mathrm{~mm}=$ $400 \mathrm{~mm}^{2}$. When supplied with a pressure $P$, a force 


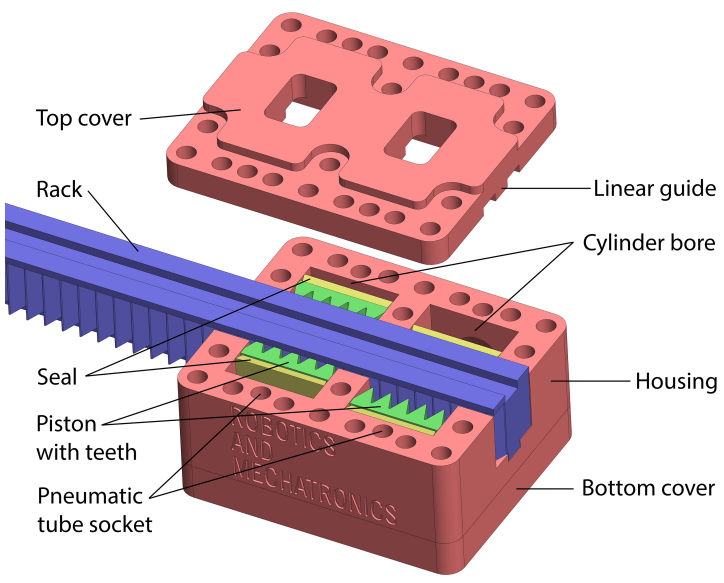

Fig. 5: T-63 view, with lifted top cover.

$F_{p}=P \cdot A=4 \cdot 10^{-4} \cdot P$ is exerted on the piston. The teeth act on the rack by means of a wedge mechanism. A piston displacement of $2.5 \mathrm{~mm}$ results in $1 \mathrm{~mm}$ rack displacement, so the wedge ratio is $\alpha=\frac{2.5 \mathrm{~mm}}{1 \mathrm{~mm}}=2.5$ and the force transferred from piston to the rack is increased by this factor. Ignoring friction, the output force $F_{r}$ satisfies $F_{r}=\alpha F_{p}=10^{-3} \cdot P=$ $1000 \mathrm{~N} / \mathrm{MPa}$. At a pressure of $P=0.3 \mathrm{MPa}$, the output force will then be $F_{r}=300 \mathrm{~N}$. The actual output force is less due to friction losses between moving parts (seals, pistons, rack), which can be determined experimentally.

The T-63 serves as a proof-of-concept, but does not meet the dimensionality requirement of a medical robot application. Therefore, a miniaturized version of the T-63 has been developed, resulting in the T-49 design. This motor has a smaller cross-sectional area and teeth depth, and has a length of $49 \mathrm{~mm}$.

\section{F. $R-80$ rotational motor}

The R-80 is a rotational stepper motor. See Figure 6 for the CAD design and Figure 1b (left) for the realization. The top and bottom covers were laser-cut from transparent acrylic plates to make the internal parts visible from the outside, all other rigid parts were 3-D printed in PLA with the Ultimaker 2 machine. The two pistons act on a gear to rotate it around, requiring the piston movement to be perpendicular to the gear tip's motion profile. Therefore, the two identical pistons have to be placed in a cross configuration, embracing the axle, and the pistons have a slotted hole for the axle.

Dimensions are $80 \mathrm{~mm} \times 80 \mathrm{~mm} \times 37 \mathrm{~mm}$ and the bore size is $30 \times 20 \mathrm{~mm}=600 \mathrm{~mm}^{2}$, resulting in $60 \mathrm{~N}$ of force per $0.1 \mathrm{MPa}$ pressure. The gear has nine teeth, with circular pitch $40^{\circ}$ and teeth depth $8 \mathrm{~mm}$. The step size is $10^{\circ}$, equal to one quarter of the circular pitch. Upon a piston movement of $x=4 \mathrm{~mm}$, the gear rotates by $\beta=10^{\circ}$. The torque $T$ as function of pressure $P$ can be found using the work balance $T \beta=F x=P A x$, so: $T=P \frac{6 \cdot 10^{-4} \cdot 4 \cdot 10^{-3}}{10 \cdot \pi / 180} \approx 1.38 \cdot 10^{-5} P=$ $13.8 \mathrm{Nm} / \mathrm{MPa}$. For a pressure of $0.3 \mathrm{MPa}$, the theoretical output torque (ignoring friction losses) is $4.1 \mathrm{~N} \mathrm{~m}$.

In an optimal situation, the piston teeth surface keeps maximal contact with the gear when sliding on it. However,

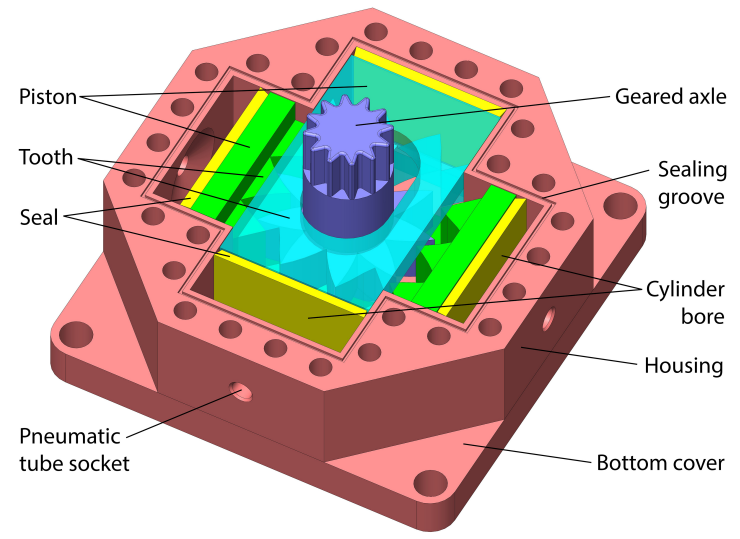

Fig. 6: R-80 view, without top cover, and one piston made transparent.

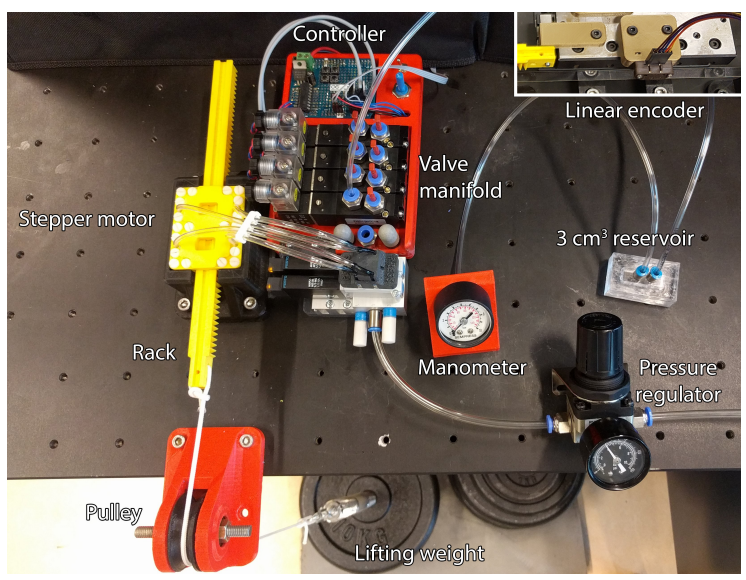

Fig. 7: Setup for force measurements.

unlike in the linear stepper motor designs, there is no ideal solution for the shape of the planar contact curve. Curved segments that keep full contact when sliding, must be circular or linear. But if the angle between the tangent and radial line is to be kept constant, the curve must be a logarithmic spiral which does not have a constant radius of curvature. Combined with the fact that a single tooth has to transfer the full load, the consequence is that the piston and rack have a relatively small effective contact surface area, compared with linear stepper motors.

As with the T-63, a miniaturized version of the R- 80 has been developed to meet the dimensional requirements for applications in MR safe robotics. The R-44 motor (Figure 1b, middle) measures $44 \mathrm{~mm}$ and was printed with the Ultimaker 2 in PLA material, while the R-25 motor (Figure 1b, right) measures $25 \mathrm{~mm}$ and was printed with the Stratasys (Stratasys Ltd., Eden Prairie, MN, USA) Objet Eden260 in FullCure720 material.

\section{MEASUREMENTS}

\section{A. Methods and setups}

Twelve experiments have been conducted, to characterize various aspects of the five motors. Measurement setups were constructed for different motor characterization, teeth strength, 
tube propagation delay and MR safety tests. This section describes the methods and setups used for the different experiments.

Figure 7 shows the general measurement setup for evaluating different motors. Constant force loads on linear stepper motors are generated by lifting combinations of weights of known mass using a pulley. Winches with radius $20 \mathrm{~mm}$ or $50 \mathrm{~mm}$ allow to convert these forces to torques to load rotational stepper motors. The system pressure is adjusted using a manual pressure regulator and measured with an analog or digital manometer. The stepping frequency is controlled by an analog turn knob connected to the Arduino controller of the valve manifold, its frequency setting was communicated over a serial interface to a laptop and displayed on its screen. Acceleration is kept below $0.4 \mathrm{~m} / \mathrm{s}^{2}$, to reduce the variation in rope tension. The Arduino keeps an internal step counter and allows to define two preset positions for feedforward position control. The directly actuated valves are of type Festo MHP2-MS1H-5/2-M5, with average response time of $1.8 \mathrm{~ms}$ and nominal flow rate of $90 \mathrm{~L} / \mathrm{min}$. For transient positional measurements, an incremental optical linear encoder of type EM2-0-1000-I (US Digital, Vancouver, WA, USA) with a resolution of $0.00635 \mathrm{~mm}$, and an absolute angular encoder of type Novotechnik P4501A502 (Novotechnik, Southborough, MA, USA), sampled with the 10-bit ADC of an Arduino for an effective resolution of $0.34^{\circ}$, were used. For measuring precise linear displacements, the mechanism of a digital caliper (length $150 \mathrm{~mm}$ and accuracy $0.01 \mathrm{~mm}$ ) was rigidly attached to the rack and table by means of custom 3-D printed parts.

1) Teeth strength: To study the optimal teeth shape for the T-63 motor, stress and deformations were simulated by applying a $100 \mathrm{~N}$ load on three different tooth shapes, with depth $5 \mathrm{~mm}, 8 \mathrm{~mm}$ and $12 \mathrm{~mm}$, and all having pitch $4 \mathrm{~mm}$ and width $14 \mathrm{~mm}$. To validate the simulation results, a deflection measurement experiment with teeth depth $12 \mathrm{~mm}$ was also carried out, in which the tooth was loaded with a $10 \mathrm{~kg}$ mass. Furthermore, the maximum load on R-80's gear was investigated by simulations.

2) Tube propagation delay: To study the delay and rise/fall times, the pressure step response for $4 \mathrm{~mm}$ tubes with inner diameter $2.5 \mathrm{~mm}$ and lengths $0.20 \mathrm{~m}, 1.0 \mathrm{~m}$ and $5.0 \mathrm{~m}$ were measured by applying square waveforms on its input and recording the transient output pressure. This was performed both without and with a $3.0 \mathrm{~cm}^{3}$ reservoir at its end, resulting in six different waveforms from which the delay and rise/fall times were derived and analyzed.

3) Force/torque versus pressure: (all motors): The weight was varied and the pressure adjusted to the lowest level where the motor could just lift the given weight without missing steps, at low frequency $(1 \mathrm{~Hz})$ and short tubes $(0.20 \mathrm{~m})$. Also, the effect of varying tube length on force/torque was studied by measuring the minimum required pressure for different tube lengths.

4) Maximum unloaded speed: (all motors): Stepping frequency was increased until the motor misses steps. This could be observed by moving between two preset step count positions, and checking that the actual preset positions do not drift away. Short $(0.20 \mathrm{~m})$ tubing was used and pressure was adjusted such that the stepping frequency could be pushed to the highest level.

5) Force versus pressure at different stepping frequencies: (T-49 only): The weight and stepping frequency were varied and the pressure was adjusted to the lowest level where the motor could just lift the given weight without missing steps. Short tubes $(0.20 \mathrm{~m})$ were used.

6) Force versus speed for different tube lengths: (T-49 only): The pressure was fixed at $0.55 \mathrm{MPa}$ and the maximum stepping frequency was determined for all combinations of weight $(0 \mathrm{~N}, 35 \mathrm{~N}, 70 \mathrm{~N}, 100 \mathrm{~N})$ and tube length $(0.20 \mathrm{~m}, 1.0 \mathrm{~m}$, $5.0 \mathrm{~m})$.

7) Maximum power: (all motors): Possible combinations of stepping frequencies, weight load and pressure were tested to find the maximum power operating point for the motor.

8) Airflow: (T-49 only): The standard airflow was measured by filling a $14 \mathrm{~L}$ tank to a pressure of $0.6 \mathrm{MPa}$, and then operating a motor until the tank pressure drops to $0.5 \mathrm{MPa}$, while the system pressure was maintained at $0.4 \mathrm{MPa}$. By recording the duration of motor operation, the flow rate is derived. This is first performed at zero frequency (idle) to derive the amount of leakage, and then for three different tube lengths $(0.20 \mathrm{~m}, 1.0 \mathrm{~m}$ and $5.0 \mathrm{~m})$ in combination with three different stepping frequencies, to derive the air volume consumption per step.

9) Overshoot: (T-63 and R-80): In order to investigate possible overshooting of the motors, the transient displacement of the R-80 and T-63 were recorded with encoders and subsequently analyzed.

10) Positional accuracy: (T-63 only): Precise actual displacements were measured over a range of setpoint positions, and its differences analyzed.

11) Durability: (T-63 only): The motor was operated for one hour, lifting and lowering a $120 \mathrm{~N}$ load over a distance of $120 \mathrm{~mm}$ in a cycle of ten seconds, delivering $6 \mathrm{~W}$ of power in a duty cycle of $50 \%$ at $0.4 \mathrm{MPa}$ pressure. The piston mass was measured before and after the test, to quantify the amount of wear in the pistons.

12) MR classification: (T-63 only): The appropiate MR compatibility classification is primarily determined by analyzing the complete list of materials that the motor is made of. Additionally, MRI scans of the motor inside an Esaote G-scan Brio 0.25T MRI scanner next to a geometric phantom (water solution containing $\mathrm{NiCl}_{2}$ and $\mathrm{NaCl}$ ) were taken and analyzed.

\section{B. Results}

This section describes the results of the twelve experiments described in the previous section.

1) Teeth strength: Figure 8 (left) shows the result of the stress simulation, as carried out with Solidworks (Dassault Systems Solidworks Corp., MA, USA). The $5 \mathrm{~mm}$ tooth has a displacement at the tip of less than $0.03 \mathrm{~mm}$ and a maximum stress of $9.6 \mathrm{MPa}$. The $8 \mathrm{~mm}$ tooth has a displacement of $0.10 \mathrm{~mm}$ and maximum stress $14 \mathrm{MPa}$. Finally, the $12 \mathrm{~mm}$ tooth has an excessive displacement of $0.36 \mathrm{~mm}$ and a maximum stress of $29 \mathrm{MPa}$.

To validate the simulation, a measurement was conducted by applying a $100 \mathrm{~N}$ load on a $12 \mathrm{~mm}$ tooth. Figure 8 (right) shows 


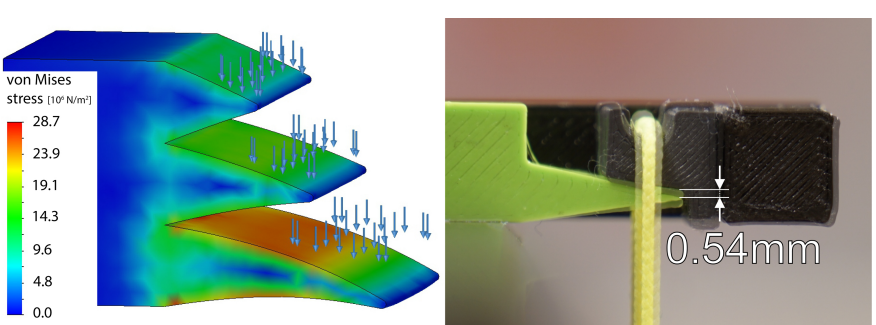

Fig. 8: Left: Stress simulation on three teeth, with depths $5 \mathrm{~mm}, 8 \mathrm{~mm}$ and $12 \mathrm{~mm}$. Deformation scale is 5.22 . Right: Tip displacement measurement. Tooth depth is $12 \mathrm{~mm}$. Photos with and without $100 \mathrm{~N}$ load are superimposed.

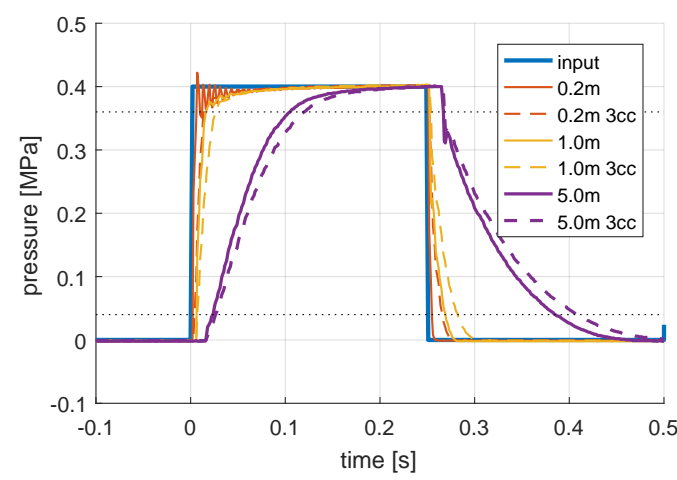

Fig. 9: Pressure step response for three different tube lengths, with and without $3 \mathrm{~cm}^{3}$ reservoir.

that the measured deflection at the tip was $0.54 \mathrm{~mm}$. This is $50 \%$ higher than the simulated value of $0.36 \mathrm{~mm}$, which could be attributed to the inhomogenity of the material resulting from the layered 3-D printing process. Using this figure, the effective Young's modulus of the material is $2.2 \mathrm{GPa}$.

Simulations on the R-80 gear have shown that a $330 \mathrm{~N}$ load on one tooth causes a stress of $45 \mathrm{MPa}$ which exceeds the working stress. The maximum allowable force was found to be $190 \mathrm{~N}$, which corresponds to a torque of $2.3 \mathrm{Nm}$ on its axle.

\begin{tabular}{c|c|c|c} 
Case & Volume & Delay & Rise/fall time \\
\hline $0.2 \mathrm{~m}$ & $1.0 \mathrm{~mL}$ & $3 \mathrm{~ms}$ & $4 \mathrm{~ms}$ \\
$0.2 \mathrm{~m}+3 \mathrm{~cm}^{3}$ & $4.0 \mathrm{~mL}$ & $3 \mathrm{~ms}$ & $10 \mathrm{~ms}$ \\
$1.0 \mathrm{~m}$ & $4.9 \mathrm{~mL}$ & $7 \mathrm{~ms}$ & $13 \mathrm{~ms}$ \\
$1.0 \mathrm{~m}+3 \mathrm{~cm}^{3}$ & $7.9 \mathrm{~mL}$ & $7 \mathrm{~ms}$ & $25 \mathrm{~ms}$ \\
$5.0 \mathrm{~m}$ & $24.5 \mathrm{~mL}$ & $18 \mathrm{~ms}$ & $100 \mathrm{~ms}$ \\
$5.0 \mathrm{~m}+3 \mathrm{~cm}^{3}$ & $27.5 \mathrm{~mL}$ & $18 \mathrm{~ms}$ & $116 \mathrm{~ms}$
\end{tabular}

TABLE II: Average delay and rise/fall time measurements for three different tube lengths.

2) Tube propagation delay: The step response of the piston pressure was measured for six different cases. Figure 9 shows the pressure graphs as function of time. For each length, the tube was either closed at the end, or connected to a $3.0 \mathrm{~cm}^{3}$ reservoir at the end (simulating the cylinder stroke volume of the T-63 motor). It can be observed that longer tubes have slower response. In case of the shortest tube without reservoir, the pressure response shows underdamped oscillatory behaviour.

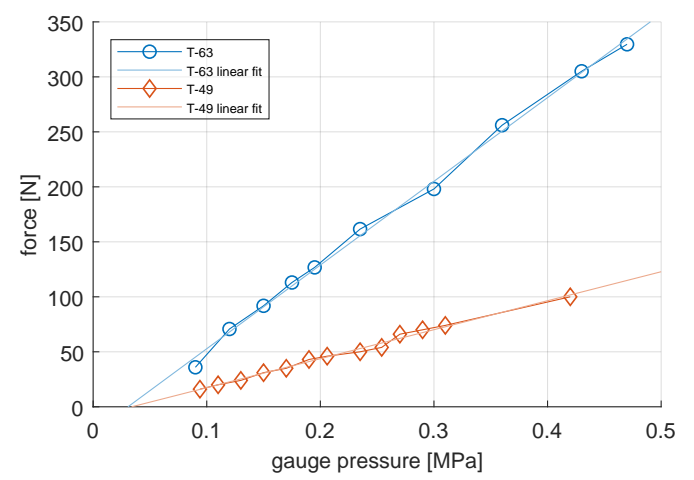

(a) T-63 and T-49 force versus pressure.

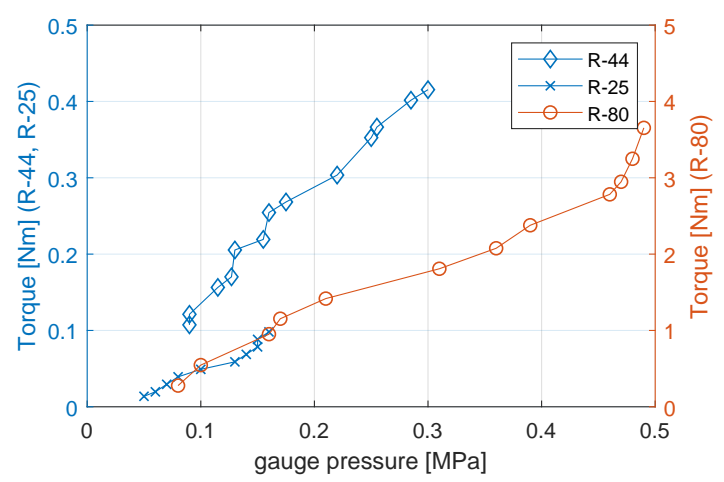

(b) R-80, R-44 and R-25 torque versus pressure.

Fig. 10: Force/torque versus pressure measurement results for linear and rotational stepper motors.

Table II lists the average delay and rise/fall time for each of the six cases. The delay is caused by the switching time of the MHP2-MS1H-5/2-M5 valve, which is $1.8 \mathrm{~ms}$, plus the propagation delay caused by the speed of sound, which is $340.3 \mathrm{~m} / \mathrm{s}$. In case of the $5.0 \mathrm{~m}$ tube, the measured delay of $18 \mathrm{~ms}$ is consistent with the theoretical value of $0.0018+\frac{5.0}{340.3}=16 \mathrm{~ms}$. The measured rise/fall times are approximately proportional to the tube volume; the measured time of $100 \mathrm{~ms}$ for the $5.0 \mathrm{~m}$ tube is consistent with the earlier calculated value of $67 \mathrm{~ms}$, because actual airflow drops when pressure approaches its setpoint.

3) Force/torque versus pressure: Figure 10a shows the force characteristics of both linear stepper motor designs, and Table I the highest measured force or torque for each motor, for $0.20 \mathrm{~m}$ short tubes. The T-63 is capable of delivering $330 \mathrm{~N}$ of force, while the T-49 was tested up to $100 \mathrm{~N}$.

The linear fitting equation of the T-63 force graph is $F=761 \cdot 10^{-6} P-23.3 \mathrm{~N}$, with $F$ in Newton and $P$ in Pascal. Its coefficients are the slope $761 \mathrm{~N} / \mathrm{MPa}$ and offset $-23.3 \mathrm{~N}$. The coefficient of determination is $R^{2}=0.9973$, which indicates its linearity. Compared with the theoretical model of $1000 \mathrm{~N} / \mathrm{MPa}$, we see that the T-63 has a mechanical efficiency of $\frac{761 \mathrm{~N} / \mathrm{MPa}}{1000 \mathrm{~N} / \mathrm{MPa}}=76 \%$. This is the ratio of work performed by the rack, to work performed by the pressurized air on the piston in the cylinder. The remaining work is lost due to friction in sliding parts, and converted to heat.

The T-49 force graph has a linear fitting equation of 
$F=264 \cdot 10^{-6} P-8.9 \mathrm{~N}$. Its coefficients are the slope $264 \mathrm{~N} / \mathrm{MPa}$ and offset $-8.9 \mathrm{~N}$. The coefficient of determination is $R^{2}=0.9920$, which also indicates its linearity. The mechanical efficiency is $\frac{264 \mathrm{~N} / \mathrm{MPa}}{400 \mathrm{~N} / \mathrm{MPa}}=66 \%$, which is lower than the efficiency of the T-63. Comparing the force/pressure graphs of the T-63 and T-49, we see that the T-63 motor is a factor $\frac{761 \mathrm{~N} / \mathrm{MPa}}{264 \mathrm{~N} / \mathrm{MPa}} \approx 2.9$ stronger than the T-49 motor.

When $5.0 \mathrm{~m}$ long tubes are used, the $\mathrm{T}-63$ was found to consistently require an additional $0.02 \mathrm{MPa}$ of pressure to lift a given weight, which can be attributed to the pressure drop in long tubes at steady airflow resulting from small air leakages in the motor.

Figure $10 \mathrm{~b}$ gives the torque characteristics of the three rotational stepper motor designs. The R-80 is capable of exerting $3.7 \mathrm{Nm}$ of torque, at a higher load (approximately $4 \mathrm{~N} \mathrm{~m}$ ) one tooth broke off. The simulated stress at that point was approximately $45 \mathrm{MPa}$, so this is the effective yield strength under dynamic loading. Using a design stress of $26 \mathrm{MPa}$, the maximum torque reduces to $2.3 \mathrm{~N} \mathrm{~m}$.

The R-44 exerted over $0.48 \mathrm{~N}$ m of torque before breaking down. The R-25 was tested up to $0.10 \mathrm{~N} \mathrm{~m}$, which is also close to its point of breakdown.

Again, all characteristic curves in Figure 10b are approximately linear.

The mechanical efficiency of the R-80 is $\frac{6.91 \mathrm{Nm} / \mathrm{MPa}}{13.8 \mathrm{Nm} / \mathrm{MPa}}=$ $50 \%$, the mechanical efficiency of $\mathrm{R}-44$ is $\frac{1.44 \mathrm{Nm} / \mathrm{MPa}}{2.29 \mathrm{Nm} / \mathrm{MPa}}=$ $63 \%$ and R-25's mechanical efficiency is $\frac{0.68 \mathrm{Nm} / \mathrm{MPa}}{1.03 \mathrm{Nm} / \mathrm{MPa}}=66 \%$. Although smaller pistons have a larger perimeter-to-surface ratio, the mechanical efficiency seems not to be directly related to the size of the motor. Variations in the choice of materials, the manufacturing process and specific teeth geometries seem to have a more dominant effect on the friction and the relative mechanical efficiencies.

4) Maximum unloaded speed: The maximum unloaded stepping frequencies are listed in Table I. The T-49 is the fastest with 320 steps/s, and R-80 the slowest with 80 steps/s.

5) Force versus pressure at different stepping frequencies: Figure 11a shows the force/pressure relationship of the T-49 motor for different stepping speeds. At low speeds, the graph follows the one in Figure 10a. For stepping frequencies up to $150 \mathrm{~Hz}$, the maximum force of $100 \mathrm{~N}$ can still be exerted if the pressure is increased. But at higher stepping frequencies $(200 \mathrm{~Hz}$ and higher), the maximum force is significantly reduced.

6) Force versus speed for different tube lengths: Figure $11 \mathrm{~b}$ shows T-49's force-speed relationship for different tube lengths (outer diameter $4 \mathrm{~mm}$, inner diameter $2.5 \mathrm{~mm}$ ), at a pressure of $0.55 \mathrm{MPa}$. As expected, using $5.0 \mathrm{~m}$ long tubes restricts operation to lower stepping frequencies (order of $10 \mathrm{~Hz}$ ) than when $0.20 \mathrm{~m}$ or $1.0 \mathrm{~m}$ tubes are used (order of $100 \mathrm{~Hz}$ ).

7) Maximum power: The maximum power found for each motor is given in Table I. Short tubes $(0.20 \mathrm{~m})$ were used. The pressure was generally set to $0.5 \mathrm{MPa}$, except for the R44 and R-25 where the pressure was lower in order not to damage the gears. The T-63 and R-80 turned out to be the most powerful motors, both delivering around $25 \mathrm{~W}$. The R44 delievered a stable $3.7 \mathrm{~W}$ of power. When the frequency

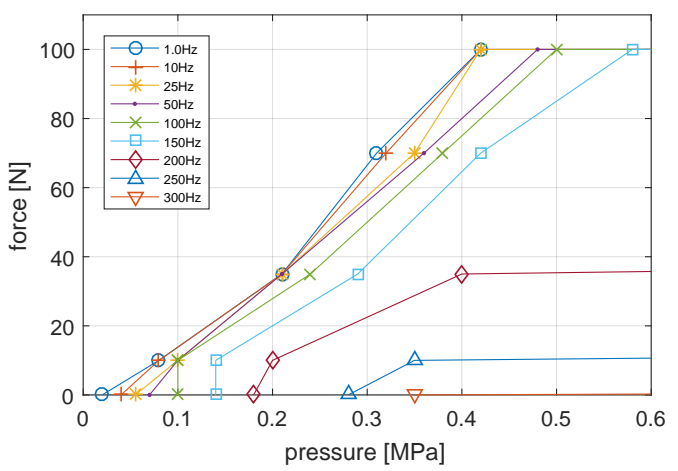

(a) T-49 force vs. pressure for different stepping speeds.

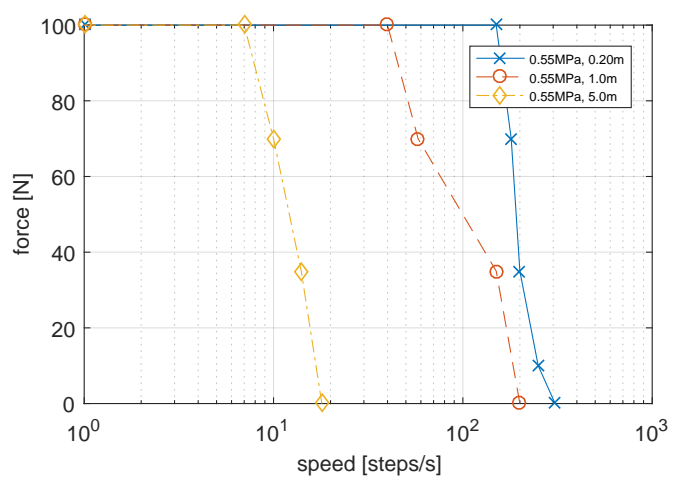

(b) T-49 force vs. speed for different tube lengths.

Fig. 11: T-49's relationships between force, pressure, speed and tube length.

\begin{tabular}{c|c|c|c} 
Tube length & Measured air volume & Tube+bore volume & Efficiency \\
\hline $0.20 \mathrm{~m}$ & $(13 \pm 2) \mathrm{mL}$ & $2.1 \mathrm{~mL}$ & $12 \%$ \\
$1.0 \mathrm{~m}$ & $(30 \pm 8) \mathrm{mL}$ & $6.0 \mathrm{~mL}$ & $5.2 \%$ \\
$5.0 \mathrm{~m}$ & $(140 \pm 10) \mathrm{mL}$ & $26 \mathrm{~mL}$ & $1.1 \%$
\end{tabular}

TABLE III: Air consumption per step in the T-49 motor and tube+bore volume, and pneumatic efficiency, for different tube lengths.

was increased from $75 \mathrm{~Hz}$ to $125 \mathrm{~Hz}$, delivering $6.2 \mathrm{~W}$ for a short time, the gear broke down. The R-25 managed to deliver $1.1 \mathrm{~W}$ of power, and also broke down when the frequency was increased further.

8) Airflow: The T-49's airflow at standstill and a pressure of $0.4 \mathrm{MPa}$ was measured to be $(250 \pm 10) \mathrm{mL} / \mathrm{s}$ on average (normalized to atmospheric pressure). This is the amount of air leaking through the housing and covers, and along the seals of the T-49. The leakage of other motors varies from $34 \mathrm{~mL} / \mathrm{s}$ for the R-25, to $424 \mathrm{~mL} / \mathrm{s}$ for the T-63.

The measured air volume consumption (normalized to atmospheric pressure) per step by the T-49 motor is listed in the second column of Table III. This amount of air is needed to increase the pressure in the tube, cylinder bore and valve by $0.4 \mathrm{MPa}$, and is indeed just over four times the calculated geometric volume. As the effective piston stroke distance is $2.0 \mathrm{~mm}$ and piston area is $196 \mathrm{~mm}^{2}$, the effective stroke volume is $0.392 \mathrm{~mL}$, requiring $1.57 \mathrm{~mL}$ of air. The pneumatic efficiency is the ratio between this volume and the measured step volume, and listed in the last column of 


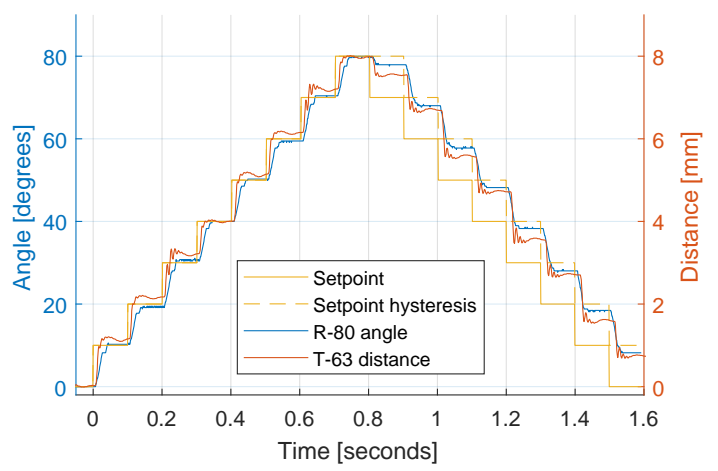

Fig. 12: Transient angle measurements of the T-63 and R-80 motors.

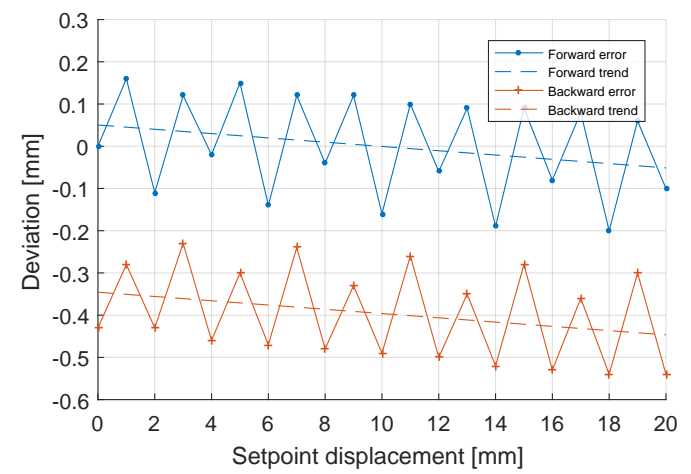

Fig. 13: Displacement error of the T-63 motor, in forward and backward direction.

Table III. As expected, the efficiency is highest for short tubes. For a given tube length and valve airflow, these figures determine the maximum stepping frequency. For $5.0 \mathrm{~m}$ tubes and a nominal airflow of $90 \mathrm{~L} / \mathrm{min}=1.5 \mathrm{~L} / \mathrm{s}$, the maximum stepping frequency is $8.9 \mathrm{~Hz}$ (ignoring delay and friction effects in the tubes). This is consistent with measurements on the pressure step response and maximum stepping frequency.

9) Overshoot: Figure 12 shows the transient measurements of the T-63 and R-80 motors. In forward motion, the overshoot of the R-80 is observed to be $0.3^{\circ}$ on average, which is in the same order as the sensor resolution. The T-63 shows oscillatory behaviour in different frequencies resulting from dynamics in the mechanical system, in particular the masses of the lifting weight and the linear rail for the optical encoder. The overshoot is approximately $0.1 \mathrm{~mm}$ on average. Both overshoots are one order of magnitude smaller than the step size.

In reverse direction, the transients have the same characteristics and magnitude as in forward direction. Additionally, a hysteresis can be observed as expected. For the R-80, the offset between setpoint (without hysteresis) and measured position is $8^{\circ}-9^{\circ}$, while for the T-63 the offset is $0.6-0.7 \mathrm{~mm}$. On average, the magnitude of hysteresis is $60 \%-80 \%$ of the step size. The graph is consistent with Figure $3 \mathrm{~b}$.

10) Positional accuracy: Figure 13 shows the displacement error of the T-63 motor as function of the setpoint position

\begin{tabular}{l|l} 
Part & Material \\
\hline Housing, pistons, rack & PLA \\
Screws & Nylon \\
Seals & Silicone rubber \\
Tubing & Polyurethane \\
Glue, sealant, lubricant & Loctite 406/770/5926, petroleum jelly
\end{tabular}

TABLE IV: List of materials of T-63

(with hysteresis) between $0 \mathrm{~mm}$ and $20 \mathrm{~mm}$. The following observations can be made:

- The error depends on the movement direction. When moving backward, the controller assumes hysteresis of one step, but there is a bias of $-0.40 \mathrm{~mm}$ in the measured position which can be attributed to clearances and material stresses in the direction of movement.

- The trendline shows that the deviation decreases with $0.0051 \mathrm{~mm}$ per $\mathrm{mm}$ displacement $(0.51 \%)$. A possible cause is the shrink factor for PLA associated with the 3-D printing process, when the part is cooled off inside the printer. This could be compensated for by increasing the dimensions by a certain factor, so that the dimensions after shrinkage are more accurate.

- The deviation is periodic with an interval of four steps. At odd-numbered setpoint displacements, the deviation is consequently above the trendline, while at even-numbered ones the deviation is below the trendline. Apparently, there is a slight asymmetry causing an offset of $0.21 \mathrm{~mm}$ between the deviations of both pistons, which can be caused by 3-D printing effects.

- Taking the trendline and periodic deviations into account, the standard deviation error from that calibrated displacement is below the measurement error of $0.01 \mathrm{~mm}$.

Next, a repeatability test was performed. The rack was moved ten times between setpoint $0 \mathrm{~mm}$ and $100 \mathrm{~mm}$. The measured positions at the lower endpoint was consistently $0.00 \mathrm{~mm}$, while at the upper endpoint it measured either $99.15 \mathrm{~mm}$ or $99.16 \mathrm{~mm}$. Its difference is within the measurement error of $0.01 \mathrm{~mm}$.

The measurements show that there is a significant, but highly repeatable deviation between setpoint and actual displacement. The RMS (root mean square) error from the trend line is $0.11 \mathrm{~mm}$. After calibration of the eight different motor phases (four forward and four backward), the repeatability is in the order of $0.01 \mathrm{~mm}$.

11) Durability: The T-63 motor was operated during one hour, lifting and lowering a $120 \mathrm{~N}$ load over a distance of $120 \mathrm{~mm}$ once every ten seconds, performing 86400 steps in total. Before the test, the masses of the pistons were measured to be $5.91 \mathrm{~g}$ and $5.81 \mathrm{~g}$, respectively. After operating the motors for one hour, the measured masses were $5.91 \mathrm{~g}$ and $5.80 \mathrm{~g}$, respectively. The weight measurement error is $0.01 \mathrm{~g}$, so there was no significant change in the masses of both pistons. Visual inspection also revealed no sign of wear. The motor did not skip a single step in the test. This particular motor can therefore operate for at least one hour under the tested load, with an indication that much longer runs are possible.

12) MR classification: Table IV lists all the materials contained in the T-63. None of the listed materials are conducting, 

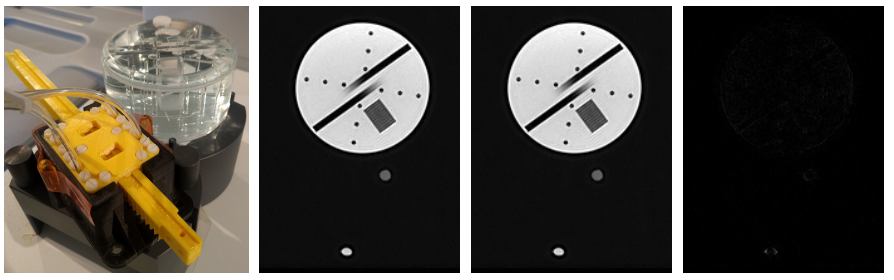

(a) Setup

(b) No motor

(c) Running

(d) Diff.

Fig. 14: MRI scans of the T-63 motor next to a geometric phantom, without motor and with running motor. The motor is placed between the two fiducials next to the phantom. Image (d) is the difference between (b) and (c).

\begin{tabular}{c|c|c|c} 
Situation & Mean intensity $\mu$ & Standard deviation $\sigma$ & SNR [dB] \\
\hline No motor & 1211 & 18.5 & 36.3 \\
Idle motor & 1204 & 19.9 & 35.7 \\
Running motor & 1190 & 18.1 & 36.4
\end{tabular}

TABLE V: Signal-to-noise ratio of bright patch in phantom, for three situations.

metallic and/or ferromagnetic, and therefore the T-63 can be classified to be MR safe.

The MR safe classification implies that the device has no potential for interaction with the magnetic field, and this was also verified with an actual MRI experiment. Figure 14 shows the setup and MRI scans of a geometric phantom and a motor holder with two fiducials attached to it. Three conditions were tested: without motor, with idle motor placed in the holder and with T-63 continuously running at $7 \mathrm{~Hz}$.

A $20 \times 20$ pixel bright patch in the image of the phantom was selected, in the proximity of the motor. The average signal intensity and standard deviation of this patch were evaluated and listed in Table $\mathrm{V}$, along with the derived signal-to-noise ratio (SNR) in decibels, for all three conditions. There is no significant change in SNR when a running motor is present, compared to the other situations.

Figure $14 \mathrm{~d}$ shows the image difference between the first and third situation. There is no change visible in the image of the phantom, on the scale of one pixel $=0.94 \mathrm{~mm}$. This implies that the presence and operation of the motor do not cause any measurable distortions in the image.

\section{Discussion}

Table I lists the developed motor's specifications alongside with state-of-the-art metal-free bidirectional pneumatic stepper motors. The T-63 motor is able to deliver $330 \mathrm{~N}$ of force, which is over ten times stronger than the two other linear stepper motors found in literature [1], [2]. The T-63 did not miss any steps and the teeth showed no signs of wear after an hour long test, which means that the motor can be feed-forward controlled and is durable. Simulations also showed that its $5 \mathrm{~mm}$ deep teeth can individually handle $100 \mathrm{~N}$ loads without excessive stress or deformations.

The R-80 rotational motor managed to deliver $3.7 \mathrm{~N} \mathrm{~m}$ when pushed for torque, or $2.3 \mathrm{~N} \mathrm{~m}$ when taking maximum material stresses into account, which is still three times stronger than the most powerful rotational motors found in literature [14], [17].

Transient positional measurements on the T-63 and R- 80 motors have shown that hysteresis is present as expected, and that the overshoot is one order of magnitude smaller than the step size. This overshoot can be considered insignificant compared to the discretization error, which is half the step size. For the T-63 motor which has a $1.0 \mathrm{~mm}$ nominal step size, deviations are present in the order of $0.1 \mathrm{~mm}-0.5 \mathrm{~mm}$, due to various manufacturing inaccuracies resulting from 3D printing. The repeatability was found to be $0.01 \mathrm{~mm}$, so a well-calibrated motor has good positional accuracy.

Comparing motors in terms of delivered power is not straightforward. There are no standardized test protocols, so wattage measurements depend on the actual setup used such as tubing dimensions and valve specifications. The PneuStep delivers $3 \mathrm{~W}$ during normal operation, but also claimed to have delivered $37 \mathrm{~W}$ when pushed for power. The R-80 and T-63 both managed to deliver $25 \mathrm{~W}$, but the long-term durability of the T-63 was evaluated at $6 \mathrm{~W}$ only. Additional measurements are needed to investigate the durability of the motor at different wattages to find out the long-term maximum operating limits. On the other hand, if we could choose stronger non-metallic materials such as PEEK or ceramics, which PneuStep also does, then the absolute operating limits would be significantly extended and the measured $25 \mathrm{~W}$ of power could then be considered to be within normal operating range.

The T-63 and R-80 are too bulky for applications in MR safe robotics. Therefore, miniaturized versions of these motors have been developed as well. As the amount of work performed per step is proportional to the stroke displacement volume, downsizing one motor design results in a performance scaled down roughly proportional to its linear dimensions.

The T-49 satisfies all requirements, delivering $100 \mathrm{~N}$ of force. One application is the Stormram 3, an MR safe robotic system for breast biopsy [3]. The R-44 and R-25 rotational motors are also compact, but not robust yet. The gears need to be re-dimensioned or constructed from stronger materials to avoid breaking down at excessive loads. The main reason is that one single tooth has to bear the full load, while in the linear motors the total load is evenly distributed over multiple teeth.

Certain applications require the valves to be placed a minimum distance away from the motors. In case of MR safe robotics, this distance is in the order of $5 \mathrm{~m}$ (except when placing the valves in a shielded enclosure within the Faraday cage of the MRI scanner). The maximum stepping frequency of the T-49 motor over a distance of $5 \mathrm{~m}$ was measured to be $7 \mathrm{~Hz}$ when maximum force is needed, which is consistent with pressure step response measurements. If this frequency is too low, then valves with higher airflow and tubes with larger inner diameter are required to increase the stepping frequency to the desired level. For distances of $1 \mathrm{~m}$, the maximum stepping frequency was measured to be $40 \mathrm{~Hz}$, and for very short tubes the T- 49 motor can be operated at up to $150 \mathrm{~Hz}$ while maintaining the maximum force of $100 \mathrm{~N}$.

After the development of Stoianovici's PneuStep in 2007, multiple attempts have been made to develop metal-free pneu- 
matic stepper motors that are compact, powerful and easy to manufacture, with limited success. Many of the previously developed motors are relatively weak or too bulky, due to the small bore sizes, inefficient mechanics, excessive leakage or other reasons.

In contrast, the designs presented in this paper show radically improved specifications and are fully rapid prototypeable. The main improvement is that the cylinders make more effective use of the available space: each cylinder bore's width is approximately one-third of the total housing length, and the bore height is approximately half the motor height, resulting in relatively large piston head surfaces resulting in high forces. The rectangular-shaped bore makes the different components rapid prototypeable, and the multifunctional pistons require no additional components to transfer the pneumatic forces to the rack or gear.

\section{CONCLUSION}

Five stepper motors have been developed: two linear and three rotational ones, in sizes ranging from $25 \mathrm{~mm}$ to $80 \mathrm{~mm}$. The T-63 and R-80 motors have shown to be significantly stronger than any other non-metallic pneumatic motor found in literature, while the T-49, R-44 and R-25 are small enough to be applied to MR safe robotics and therefore satisfy all requirements. All motors are easy to manufacture by rapid prototyping. The presented design method involving boxshaped pistons that embrace a rack or gear inside a spaceefficient housing, has shown to be the key concept that is likely to advance the field of metal-free pneumatic stepper motors towards a higher level.

\section{REFERENCES}

[1] V. Groenhuis and S. Stramigioli, "Laser-Cutting Pneumatics," in IEEE/ASME Transactions on Mechatronics, vol. 21, no. 3, pp. 1604 1611, June 2016. doi: 10.1109/TMECH.2015.2508100

[2] V. Groenhuis, J. Veltman and S. Stramigioli, "Stormram 2: A MRIcompatible pneumatic robotic system for breast biopsy," Proceedings of The Hamlyn Symposium on Medical Robotics, June 2016, Imperial College and the Royal Geographical Society, London, UK, pp. 52-53.

[3] V. Groenhuis, J. Veltman, F.J. Siepel and S. Stramigioli, "Stormram 3: An MRI-compatible robotic system for breast biopsy," in IEEE Robotics \& Automation Magazine, Special Issue on Surgical Robot Challenge, June 2017, pp. In press.

[4] Whitney, J. P., Glisson, M. F., Brockmeyer, E. L., and Hodgins, J. K., "A low-friction passive fluid transmission and fluid-tendon soft actuator." In 2014 IEEE/RSJ International Conference on Intelligent Robots and Systems (pp. 2801-2808).

[5] R. Gassert, R. Moser, E. Burdet, and H. Bleuler, "MRI/fMRI-compatible robotic system with force feedback for interaction with human motion," IEEE/ASME Trans. Mechatronics, vol. 11, no. 2, pp. 216-224, 2006.

[6] Su, H., Zervas, M., Cole, G. A., Furlong, C., and Fischer, G. S, "Real-time MRI-guided needle placement robot with integrated fiber optic force sensing." In Robotics and Automation (ICRA), 2011 IEEE International Conference on (pp. 1583-1588). IEEE.

[7] P. Moreira, S. Misra, "MR-Compatible Robot for Needle-Based Prostate Interventions." Proceedings of The Hamlyn Symposium on Medical Robotics 25-28 June 2016, Imperial College London and the Royal Geographical Society, London, UK

[8] Chapuis, D., Gassert, R., Ganesh, G., Burdet, E. A. B. E., and Bleuler, H. A. B. H, "Investigation of a cable transmission for the actuation of MR compatible haptic interfaces." The First IEEE/RAS-EMBS International Conference on Biomedical Robotics and Biomechatronics, 2006. BioRob 2006. (pp. 426-431).

[9] Felfoul, O., Becker, A., Bergeles, C., and Dupont, P. E, "Achieving commutation control of an MRI-powered robot actuator." IEEE Transactions on Robotics, 31(2), 387-399 (2015).
[10] Elhawary, H., Zivanovic, A., Tse, Z. T. H., Rea, M., Davies, B. L., Young, I, Bydder, G., Payley, M. and Lamperth, M. U., "A magneticresonance-compatible limb-positioning device to facilitate magic angle experiments in vivo." Proceedings of the Institution of Mechanical Engineers, Part H: Journal of Engineering in Medicine, 222(5), 751760 .

[11] Comber, D. B., Slightam, J. E., Barth, E. J., Gervasi, V. R., and Webster, R. J., "Design and precision control of an MR-compatible flexible fluidic actuator." In ASME/BATH 2013 Symposium on Fluid Power and Motion Control. American Society of Mechanical Engineers, 2013

[12] B. Yang, U. X. Tan, A. B. McMillan, R. Gullapalli, and J. P. Desai, "Design and control of a 1-DOF MRI-compatible pneumatically actuated robot with long transmission lines," IEEE/ASME Trans. Mechatronics, vol. 16, no. 6, pp. 1040-1048, 2011

[13] Y. Chen, C. D. Mershon, Z. Tsz, and H. Tse, "A 10-mm MR-Conditional Unidirectional Pneumatic Stepper Motor," IEEE/ASME Transactions on Mechatronics, Vol. 20, no. 2, April 2015, pp. 782-788.

[14] Stoianovici, D., Patriciu, A., Petrisor, D., Mazilu, D., and Kavoussi, L., "A new type of motor: pneumatic step motor." IEEE/ASME Transactions On Mechatronics, 12(1), 98-106, 2007.

[15] Sajima, H., Kamiuchi, H., Kuwana, K., Dohi, T., and Masamune, K., "MR-safe pneumatic rotation stepping actuator." Journal of Robotics and Mechatronics, Vol. 24, No. 5, 2012, pp. 820-827, 2012.

[16] Y. Chen, K. W. Kwok, and Z. T. H. Tse, "An MR-Conditional HighTorque Pneumatic Stepper Motor for MRI-Guided and Robot-Assisted Intervention,” Ann. Biomed. Eng., vol. 42, no. 9, pp. 1823-1833, 2014.

[17] Secoli, R., Robinson, M., Brugnoli, M., and y Baena, F. R., "A low-cost, high-field-strength magnetic resonance imaging-compatible actuator." Proceedings of the Institution of Mechanical Engineers, Part H: Journal of Engineering in Medicine, 229(3), pp. 215-224, 2015.

[18] Z. Guo, T. T. L. Lun, Y. Chen, H. Su, D. T. M. Chan, K.W. Kwok, "Novel Design of an MR-safe Pneumatic Stepper Motor for MRI-guided Robotic Interventions," Proceedings of The Hamlyn Symposium on Medical Robotics 25-28 June 2016, Imperial College London and the Royal Geographical Society, London, UK, pp. 50-51.

[19] D.G.H. Bosboom, J.J. Ftterer, and J. Bosboom, "Motor system, comprising motor and control unit, and robot arm device comprising the same," European Patent 2642938B1, issued date November 22, 2010.

[20] V. Groenhuis, F. J. Siepel, J. Veltman and S. Stramigioli, "Design and characterization of Stormram 4: An MRI-compatible robotic system for breast biopsy," 2017 IEEE/RSJ International Conference on Intelligent Robots and Systems (IROS), Vancouver, BC, 2017, pp. 928-933.

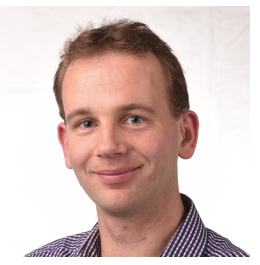

Vincent Groenhuis received his B.Sc. with honors in Computer Science in 2006 and his M.Sc. degree with honors in Embedded Systems in 2014, both at the University of Twente. He is currently pursuing a Ph.D. degree at the Department of Robotics and Mechatronics, University of Twente, Enschede, The Netherlands.

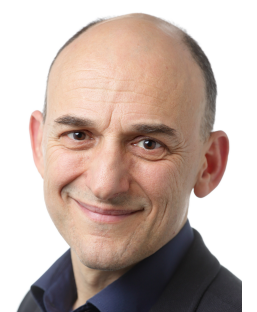

Stefano Stramigioli received the M.Sc. with honors (cum laude) in 1992 and the Ph.D with honors (cum laude) in 1998. He is currently full professor of Advanced Robotics and chair holder of the Robotics and Mechatronics group at the University of Twente. He has more than 200 publications including 4 books. He is currently the Vice President for Research of euRobotics, the private part of the PPP with the EU known as SPARC. He was the recipient in 2018 of an ERC advanced Grant. He also has a guest co-chair position at ITMO University, St. Petersburg, Russia. He has been an Officer and AdCom member for IEEE RAS. He is an IEEE Fellow. 